\title{
Chronic effects of tramadol hydrochloride/paracetamol oral administration on haematological parameters and glucose level in Wistar rats
}

\author{
Maja MITRAŠINOVIĆ-BRULIĆ 1 (D), Anida KULOVAC 1 (D), Damir SULJEVIĆ 1 * (D) \\ 1 Department of Biology, Faculty of Science, University of Sarajevo, Sarajevo, Bosnia and Herzegovina. \\ * Corresponding Author. E-mail: suljevic.damir@gmail.com (D.S.); Tel. +387-33-723 776.
}

Received: 31 December 2019 / Revised: 14 March 2020/ Accepted: 30 March 2020

ABSTRACT: Tramadol hydrochloride/paracetamol is an opioid that is composed of two different analgesics, tramadol (opioid, $37.5 \mathrm{mg}$ ) and paracetamol (non opioid, $325 \mathrm{mg}$ ). The study presents first data of tramadol hydrochloride/ paracetamol effects on haematological parameters and glucose levels in Wistar rats. Oral administration ad libitum of tramadol hydrochloride/paracetamol was administered during a twenty days period. This research includes two groups of animals. Group I include animals that were administered tramadol hydrochloride/paracetamol daily at dosage of $1.12 \mathrm{~g} / 300 \mathrm{ml}$ and group II that were administered daily at dosage of $1.68 \mathrm{~g} / 300 \mathrm{ml}$ of water. We analayzed 14 haematological parameters and glucose concentration. Significant changes were established for all analyzed parameters. Significantly low numbers of erythrocytes, leukocytes and lymphocytes were observed. Tramadol hydrochloride/paracetamol has an extremely negative effect on haematological parameters in Wistar rats, particularily on the blood coagulation due to the thrombocitopenia, anaemia and weakened immunity. If properly administered, tramadol hydrochloride/paracetamol can be an effective analgesic but at high dosage and over a prolonged period it may cause adverse effects in Wistar rats.

KEYWORDS: Tramadol hydrochloride/paracetamol; Wistar rats; haematological parameters; glucose.

\section{INTRODUCTION}

Tramadol hydrochloride/paracetamol (THP, trade name Zaracet ${ }^{\circledR}$ ) contains $37.5 \mathrm{mg}$ of tramadol hydrochloride and $325 \mathrm{mg}$ of paracetamol. Tramadol hydrochloride (tramadol) is widely spread analgesic which is administered orally and perorally. It is used to treat moderate to moderately severe pain. When taken orally in an immediate-release formulation, the onset of pain relief usually begins within an hour [1]. Tramadol acts by binding $\mu$-opioid receptors and neurons, and it is also a serotonin-norepinephrine reuptake inhibitor (SNRI) [2]. Tramadol has a central acting mechanism via serotonin receptors, in addition to the opioid receptors, that helps to achieve clinical analgesia with less of the typical side effects associated with the typical opioids acting via opioid receptors alone [3]. The most common side effects are constipation, itchiness and nausea while more serious side effects may include insomnia, drug dependency and a high risk of serotonin syndrome.

Various animal studies demonstrate that tramadol has an antinociceptive reactions on acute and chronic pain [4]. The long-term use of tramadol at high dosage causes physical dependence and withdrawal syndrome [5]. Tramadol is also used perioperatively in veterinary anesthesia as it significantly reduces the requirements of volatile anesthetics and opioid agents. Paracetamol treats pain and fever, and does not have significant antiinflammatory effects. An acute paracetamol overdose can lead to a fatal liver damage [6]. The pharmacological pain treatment of the rheumatologic conditions, especially osteoarthritis, may have serious adverse effects and low efficacy. Paracetamol is a common analgesic that many patients, especially the elderly take at a low dosage. However, the statistical data indicates that the hepatotoxicity may occur if paracetamol administration exceeds the maximum daily recommended dosage of $4 \mathrm{mg} /$ day. Data also suggests that paracetamol, administered at high dosage may add to the risk of upper gastrointestinal (GI) complications [7]. Combination analgesics are often prescribed for acute pain management as they have been shown to yield pain relief superior to single agents by either acting synergistically or targeting more than one physiological cause of the

How to cite this article: Mitrašinović-Brulić M, Kulovac A, Suljević D. Chronic effects of tramadol hydrochloride/paracetamol oral administration on haematological parameters and glucose level in Wistar rats. J Res Pharm. 2020; 24(3): 310-317. 
pain simultaneously [8]. Preclinical studies and several laboratories have demonstrated that paracetamol may have a beneficial effect on blood glucose levels, skeletal muscle function and as cardioprotective and neuroprotective agent $[9,10,11,12,13]$. These studies have suggested that these off-label applications may be derived from the ability of paracetamol to function as an antioxidant. Pain has a multifactorial origin, hence it may be difficult to achieve effective pain control with a single drug [14]. Combination therapy of analgesics from different groups is advantageous in targeting both peripheral and central pain pathways.

Therefore, it helps in production of analgesia at lower and more tolerable doses of the constituent drugs $[15,16]$. Combination therapies can have a positive influence on the ability of individual components to minimize pain, with better tolerability and reduced recovery time. The fixed-dose combination (FDC) of tramadol and paracetamol has been extensively researched and compared with other combinations. Results from preclinical studies have observed both the dual mechanism of action of tramadol and the analgesic synergy between the two compounds in this FDC [17]. According to a meta-analysis, the combination of tramadol and acetaminophen was more effective than either of its two components administered alone, with an almost similar safety profile to either of the components prescribed alone [18].

Current studies deal with the effects of paracetamol and tramadol on haematology of certain animal species while the effects of tramadol combined with paracetamol as tramadol hydrochloride/paracetamol on haematological parameters have not been researched until now. Although many studies have shown the negative effects of these two drugs, the aim of this study is to evaluate the effect of tramadol hydrochloride/paracetamol on blood glucose levels and haematological parameters in rats.

\section{RESULTS}

Table 1 presents haematological parameters values and glucose concentration for the control and experimental group of rats (experimental group I and II). One Way ANOVA method was used to determine between groups difference while the Tukey Post Hoc Test (Table 1 and 2) was used to determine within a group difference $(a, b, c)$.

RBC, WBC, PLT, HCT and MCV values are high in the control group in comparison with experimental groups. The same values decrease at higher dosage of tramadol hydrochloride/paracetamol in the experimental group. $\mathrm{HB}, \mathrm{MCH}, \mathrm{MCHC}$ and glucose values are also high in the control group while they are lower in the experimental group I, and increased again in the experimental group II. All parameters show significant difference between the groups except for the HCT value (ANOVA). Post Hoc Test determines significant difference within the group for most of the parameters, except for $\mathrm{MCH}$ (between the control and experimental group II), glucose concentration (between control and experimental group I).

Table 1. Hematological parameters values and glucose concentration.

\begin{tabular}{|c|c|c|c|c|c|c|c|}
\hline \multirow{2}{*}{ Parameters } & \multicolumn{2}{|c|}{ Control group } & \multicolumn{2}{|c|}{ Experimental group I } & \multicolumn{2}{|c|}{ Experimental group II } & \multirow{2}{*}{ ANOVA } \\
\hline & Mean & Range & Mean & Range & Mean & Range & \\
\hline RBC $\left(10^{12} / \mathrm{L}\right)$ & $6.78 \pm 0.66^{a}$ & $5.80-8.20$ & $6.68 \pm 0.85^{b}$ & $5.10-8.16$ & $3.46 \pm 0.158^{c}$ & $2.10-7.73$ & $0.00^{* * *}$ \\
\hline WBC $\left(10^{9} / \mathrm{L}\right)$ & $6.86 \pm 0.82^{a}$ & $6.00-8.00$ & $4.20 \pm 0.90^{\mathrm{b}}$ & $3.15-6.10$ & $2.88 \pm 1.17 \mathrm{c}$ & $1.10-5.55$ & $0.00^{* * *}$ \\
\hline PLT $\left(10^{9} / \mathrm{L}\right)$ & $204.8 \pm 30.96^{\mathrm{a}}$ & $159-250$ & $\begin{array}{c}123.58 \pm 13.89 \\
\text { b }\end{array}$ & 99-148 & $93.95 \pm 14.08^{c}$ & $79.80-126$ & $0.00^{* * *}$ \\
\hline HB $(g / L)$ & $167.64 \pm 18.38^{a}$ & $\begin{array}{c}138.1- \\
192\end{array}$ & $\begin{array}{c}191.01 \pm 15.56 \\
\mathrm{~b}\end{array}$ & $\begin{array}{l}171.19- \\
228.73\end{array}$ & $195.07 \pm 142.59 \mathrm{c}$ & $94.90-488.6$ & $0.00^{* * *}$ \\
\hline $\operatorname{HCT}(L / L)^{*}$ & $0.38 \pm 0.05$ & $0.32-0.48$ & $0.27 \pm 0.05$ & $0.20-0.35$ & $0.24 \pm 0.07$ & $0.13-0.33$ & 0.732 \\
\hline $\operatorname{MCV}(\mathrm{fL})$ & $56.94 \pm 9.57 \mathrm{a}$ & $\begin{array}{l}46.85- \\
76.19\end{array}$ & $41.43 \pm 7.82^{\mathrm{b}}$ & $\begin{array}{l}28.17- \\
54.10\end{array}$ & $78.59 \pm 36.68^{c}$ & $\begin{array}{l}36.22- \\
157.14\end{array}$ & $0.00^{* * *}$ \\
\hline $\operatorname{MCH}(p g)^{* *}$ & $24.90 \pm 3.48^{a}$ & $\begin{array}{l}20.22- \\
29.03\end{array}$ & $28.93 \pm 3.43^{b}$ & $\begin{array}{l}23.78- \\
35.53\end{array}$ & $50.48 \pm 20.14^{\mathrm{ac}}$ & $22.10-93.60$ & $0.003^{* * *}$ \\
\hline MCHC (g/L) & $444.66 \pm 37.38^{a}$ & $\begin{array}{c}363.54- \\
495 \\
\end{array}$ & $\begin{array}{c}713.44 \pm 104.1 \\
\mathrm{~b}\end{array}$ & $\begin{array}{l}518.76- \\
877.25 \\
\end{array}$ & $824.29 \pm 489.1^{\mathrm{c}}$ & $\begin{array}{l}287.58- \\
1809.67\end{array}$ & $0.00^{* * *}$ \\
\hline $\begin{array}{l}\text { Glucose } \\
(\mathrm{mmol} / \mathrm{L})^{* *}\end{array}$ & $3.72 \pm 0.41^{\mathrm{a}}$ & $3.10-4.30$ & $5.83 \pm 0.98^{\mathrm{ab}}$ & $4.70-8.00$ & $4.63 \pm 1.93^{c}$ & $3.45-10.70$ & $0.001^{* * *}$ \\
\hline
\end{tabular}

$a, b$ More than one value in the same row indicates statistical differences within the group

* difference within the group were not determined (HCT)

** significant differences were not determined: - between control and experimental group II for $\mathrm{MCH}$; ab - between control and experimental group I for glucose

*** statistically significant difference at 0.05 level 
Procentual white blood cell values for all three groups of rats are presented in the Table 2. Values of basophil granulocytes and eosinophil granulocytes are low in all three groups of rats. Lymphocyte numbers are lower in the experimental group, particularly in the group I. Monocyte values are increased in both experimental groups, especially in group I. Segmented neutrophils values are decreased in both experimental groups while the nonsegmented neutrophils are increased in group I. Significant differences are determined for all parameters $\left({ }^{* * *}\right)$, while the differences within the group $\left(^{* *}\right)$ for lymphocytes numbers were not determined between the control group and the experimental group I.

Table 2. White blood cells values (\%).

\begin{tabular}{|c|c|c|c|c|c|c|c|}
\hline \multirow[t]{2}{*}{ Parameters } & \multicolumn{2}{|c|}{ Control group } & \multicolumn{2}{|c|}{ Experimental group I } & \multicolumn{2}{|c|}{$\begin{array}{l}\text { Experimental group } \\
\text { II }\end{array}$} & \multirow[t]{2}{*}{ ANOVA } \\
\hline & Mean & Range & Mean & Range & Mean & Range & \\
\hline $\begin{array}{l}\text { Nonsegmented } \\
\text { neutrophyles }\end{array}$ & $5.40 \pm 2.07 a$ & $3-9$ & $10.58 \pm 6.02^{b}$ & $4-20$ & $5.29 \pm 4.34^{c}$ & $3-15$ & $0.018^{* * *}$ \\
\hline $\begin{array}{l}\text { Segmented } \\
\text { neutrophyles }\end{array}$ & $28.90 \pm 6.61^{\mathrm{a}}$ & $19-38$ & $19.67 \pm 8.82^{b}$ & $7-35$ & $19.08 \pm 3.58 \mathrm{c}$ & $12-23$ & $0.019 * * *$ \\
\hline Eosinophiles & $1.67 \pm 0.82^{\mathrm{a}}$ & $1-3$ & $2.83 \pm 2.25 b$ & $1-7$ & $2.60 \pm 1.17 \mathrm{c}$ & $1-4$ & $0.00^{* * *}$ \\
\hline Basophiles & $\leq 1$ & & $\leq 1$ & & $\leq 1$ & & - \\
\hline Lymphocytes ** & $62 \pm 6.41^{\mathrm{a}}$ & $53-75$ & $44.17 \pm 19.42^{\mathrm{ab}}$ & $30-76$ & $57.33 \pm 9.55^{c}$ & $45-68$ & $0.01^{* * *}$ \\
\hline Monocytes & $2.40 \pm 1.35^{\mathrm{a}}$ & $1-5$ & $5.25 \pm 1.28 b$ & $4-7$ & $8.25 \pm 2.75^{c}$ & $5-11$ & $0.00 * * *$ \\
\hline
\end{tabular}

$a, b$ More than one value in the same row indicates statistical differences within the group

** ab -no significant changes for lymphocyte values between control and experimental group I were determined

*** - statistically significant differences between the groups, ANOVA at 0.05

\section{DISCUSSION}

Tramadol hydrochloride/paracetamol (THP) consists of two analgesics tramadol and paracetamol and it treats moderate to severe pain. Paracetamol is a non opioid that treats mild and strong pain while tramadol is an opioid that treats moderate and very severe pain and it mostly affects psycho physiological abilities. The effects of THP on hematological and biochemical paremeters are not well known. Our study will therefore focus on recent research on the effects of paracetamol and tramadol individually.

Our study indicates that one of the side effects of THP is a very low thrombocyte count. Some studies found severe cases of thrombocytopenia following the paracetamol over dose (paracetamol levels in blood were $250 \mathrm{mg} / \mathrm{L}$ ) during the period of two days [19]. Our study also determines severe thrombocytopenia while administering small dosage of THP while the high dosage during a prolonged period causes severe problems. Tramadol combined with paracetamol increases thrombocytopenia which is possibly caused by the toxic effect of THP or its metabolite on thrombocyte count. Other medications such as Panadol extra significantly lower thrombocyte count and damage blood coagulation. Other haematological parameters were not effected [20,21]. Determined that paracetamol leads to thrombocytopenia and leucopenia that confirms our findings. Oral administration of paracetamol $(333 \mathrm{mg} / \mathrm{kg})$ in mice led to the significantly increased glucose and leukocyte numbers while erythrocyte count and haemoglobin concentration were decreased. Neutrophil values were considerably lower while the lymphocyte count was higher.

Administration of aspirin $(620 \mathrm{mg} / \mathrm{kg})$ had the same side effects. These two non steroid antiinflammatory drugs (NSAIDs) showed congested and hyalinized liver, enlarged kidney and spleen, hemorrhagic stomach and ulcerated intestine in dead mice [22].

Our findings establish decreased leukocyte values while THP at higher dosage increases glucose levels. Bhaumika and Sharme [23] determined considerable changes in glucose levels by administering Liv 52 extract in sheep. Some studies determined an increase of serum glucose in mice by administering Liv 52 extract and Pioglitazone [24]. Increased glucose values could occur due to the release of glucocorticoids from the medications and their binding to plasma proteins. This process increases glycogenesis, decreases protein synthesis and peripheral glucose utilization [25]. Low glucose levels could also be a result of a prolonged administration of medication that lowers glycogen. Behavioral changes in rats (increased hyperactivity and alertness) could additionally deplenish glucose reserves.

Paracetamol $(7.5 \mathrm{mg} / \mathrm{kg})$ caused lymphocytopenia, low erythrocyte count as well as low HCT and haemoglobin values in albino rats, which corresponds our findings [26]. Our study observes considerably high neutrophil count. Paracetamol combined with tramadol causes reduction of leukocytes, neutrophils and 
especially lymphocytes which indicates a very serious weaking of an immune system. Erythrocyte count is low as well. Higher dose of THP leads to an increase of haemoglobin. Low dosage of THP $(1.12 \mathrm{~g} / 300 \mathrm{ml})$ decreased haemoglobin concentration in the control group. Some studies observed reduction of erythrocytes numbers and haemoglobin concentration in their research [27,28]. Administering $300 \mathrm{mg} / \mathrm{kg}$ of paracetamol during a twoday period significantly reduced erythrocyte numbers and haematocrit values, while it decreased leukocytes numbers in Wistar rats [29]. These findings are very similar to our data. Reduction of erythrocytes numbers and haemoglobin concentration can also be impacted by the reduced erythrocyte life span and the oxidation of hemoglobin into methemoglobin and sulfhemoglobin caused by NSAID [30]. Samuel et al. [29] observed that the reduction of erythrocytes as a result of administering high dosage of paracetamol could also be effected by the destruction of ripe erythrocytes as well as the release of erythropoetin from kidneys. Haematocrit reduction could indicate anemia.

Our research also indicates presence of anemia. In regards to the reduced erythrocyte numbers and hemoglobin concentration, $\mathrm{MCV}$ is decreased [31]. When the MCV values are reduced, erythrocytes are also lower than normal (microcytic). Secondly, it is evident that the increase in erythrocyte volume leades to the increase of hemoglobin concentration. Therefore, MCHC values is very high at high THP dosage. This mechanism is necessary for maintaing oxidation process and energy balance. Paracetamol significantly reduces hemoglobin concentration which indicates reduction in the oxygen-carrying capacity of blood and the amount of oxygen delivered to the tissues in rats handled by Aptenia cordifolia and Securinega virosa extracts [32].

Oral administration of tramadol in rabbits resulted in hematological changes such as an increased WBC and MCV values while the haematocrit values, haemoglobin concentration, $\mathrm{RBC}, \mathrm{MCH}, \mathrm{MCHC}$ and thrombocytes were considerably reduced. Tramadol seems to effect defense mechanism and an immune system of rabbit [33].

Tramadol combined with paracetamol such as THP, has a very negative impact on the immune system of Wistar rats. Opioids may supress immune system cells such as leukocytes and lymphocytes through the intermediary mechanism that affects the central nervous system [34].

Lymphoid organs contain rich supply of sympathetic nerves that directly enable norepinephrine to influence lymphocyte actions. Tramadol inhibits neuronal reuptake and 5-hydroxytryptamine (5-HT) and it can actually relieve the release of 5-HT [35].

Consequently, we determined that neutrophil value increased inciting lymphocyte supression. Some studies report that the prolonged usage of tramadol increases risk of liver and kidney damage in people [36]. We also established a mild increase in glucose levels. Tramadol may indirectly have an important effect on carbohydrates metabolism, most likely due to the elevated gluconeogenesis and glucose mobilization [37]. The glucose concentration lowers at high tramadol concentration [38]. Tramadol may lower glucose levels in diabetic rats through the activation of opioid $\mu$-receptors [39]. Tramadol act as serotonin reuptake inhibitor and hypoglycemia has been described with some serotonin antidepressant sertraline [40]. Tramadol and paracetamol reduce erythrocyte count while the combined medication such as THP administrated at higher dosage during a prolonged period, leads to a rapid reduction in erythrocyte values particularly in the experimental group II. Elyazji et al. [33] reported low erythrocyte count to the inhibitory effects that tramadol has on histogenesis. Some studies have found reductions in RBC count and hemoglobin concentration following the tramadol treatment, which may be a result of decline of hemoglobin synthesis in the bone marrow [41]. During the intraperitoneal administration of tramadol in various dosages during the period of 30 days (50 and $100 \mathrm{mg} / \mathrm{kg}$ ), we established considerable reductions in hemoglobin concentration, RBC, haematocrit as well as an increase in leukocyte count, particularly lymphocytes and monocytes while the neutrophil count was very low [42]. Tramadol administration in dogs $(2 \mathrm{mg} / \mathrm{kg})$ led to the reduction of leukocytes and neutrophils which was observed in our study [43]. Intravenous tramadol administration in anesthetized dogs $(2 \mathrm{mg} / \mathrm{kg})$ did not result in significant changes of hematological parameters except for the reduction of $\mathrm{RBC}, \mathrm{WBC}$, hematocrit and hemoglobin concentration, presumably due to the erythrocyte sequestration in non splenic tissues. RBC, hemoglobin concentration and HCT were not considerably modified whereas the WBC was significantly reduced post tiletamine/zolazepam-xylazine-tramadol administration at dosage of $3.5 \mathrm{mg} / \mathrm{kg}$ in miniature pigs [44]. The use of tramadol in the treatment of pain must be safe and adequate. Teixeria et al. [45] reported that the combination of dipyrone and tramadol in the treatment of postoperative cat pain did not provide better analgesia than tramadol alone. 


\section{CONCLUSION}

The individual side effects of tramadol induce considerable changes of haematological parameters in relation to paracetamol. These side effects of combined medication such as THP lead to significant haematological changes. Our research indicates that prolonged or chronic administration of THP may cause severe thrombocytopenia, leading to failure of the immune system, anemia and a very low erythrocyte count. These side effects increase commensurate with the dosage and duration of the treatment. Although the opioids are effective in treating pain, their side effects during a prolonged usage need to be considered. The opioids may have different side effects in different animals. It is crucial to administer the right dosage of THP. Our research finds THP effective in treatment of pain if properly administered.

\section{MATERIALS AND METHODS}

\subsection{Animals}

Rats (Rattus norvegicus, Wistar strain) used for the purpose of this study were bred in vivarium, Laboratory for Physiology, Department of Biology, University of Sarajevo, Bosnia and Herzegovina. The animals were placed in individual cages (four animals each) at room temperature of $25^{\circ} \mathrm{C}$. They were fed Vilmie + Mr. Woodfield (rat food, Germany) and water ad libitum. This research includes three groups of rats: control $(n=10)$ and two experimental groups (group $\mathrm{I}, \mathrm{n}=12$ and group II, $\mathrm{n}=12$ ). Tramadol hydrochloride/paracetamol was administered daily at dosage of $1.12 \mathrm{~g} / 300 \mathrm{ml}$ water (experimental group I) and $1.68 \mathrm{~g} / 300 \mathrm{ml}$ of water (experimental group II) during twenty days. Handled animals were treated in accordance with the "Declaration on the Rights of Animals" (UNESCO, 1978), "Universal Declaration on Animal Welfare"(WSPA, 2000), Animal Protection and Welfare Law of Bosnia and Herzegovina ("Official Gazette" 25/09) and Ethics Committee of Faculty of Science.

\subsection{Experimental design}

Treated animals were 12 and 15 weeks old with the weight of approximately 150 and $200 \mathrm{~g}$. Anesthesia (sufentanil/medetominide 50/150 $\mathrm{gg} / \mathrm{kg}$ - administered by intramuscular injection) and euthanasia were performed at doubled dosage. The blood was collected via cardiac puncture with the small gauge needle (21G; Semikem, Sarajevo, Bosnia and Herzegovina). Approximately $2 \mathrm{ml}$ of blood was analyzed for the following haematological parameters while the caudal blood was used for glucose concentration analysis.

\subsection{Haematological techniques}

The following haematological parameters were analyzed: erythrocytes count, RBC (via Hayem solution, Semikem, Bosnia and Herzegovina); leukocyte count, WBC (via Türk reagens, Semikem, Bosnia and Herzegovina); haemoglobin concentration, HB by Drabkin's reagent as a cyanmethemoglobin standard solution (Germany) and haematocrit values, HCT (centrifuging blood samples via micro hematocrit method, 5 minutes, $16000 \mathrm{rpm}$ by Hettich Haematokrit 24 zentri-fugen, Germany). Erythrocyte indices were determined through a mathematical formula that includes: MCV (mean corpuscular volume), MCH (mean corpuscular hemoglobin) and MCHC (mean corpuscular hemoglobin concentration). Erythrocyte and leukocyte count were determined by hemocytometer chamber (Neuber's chamber) while the thrombocytes count was calculated by Fone's method. Fresh smears were stained by May-Grünwald and Giemsa stains (Semikem, Sarajevo, Bosnia and Herzegovina) for procentual analysis of leukocyte numbers in the peripheral blood. Cell identification and procentual count of blood cells were performed on Olympus BX41 light microscope.

\subsection{Blood glucose analysis}

The blood from the caudal vein was used for a blood glucose analysis. The blood was collected by puncturing the caudal vein. The blood glucose levels were determined via dry chemistry method (Ascensia Brio, Bayer Healthcare, Germany).

\subsection{Statistical}

Results were evaluated by the IBM SPSS (Version 20.0, SPSS, Inc., Chicago, IL, USA). The collected data was analyzed through the methods of the descriptive statistics (mean, standard deviation and range). Variances between the groups were analyzed via One Way ANOVA method while Post Hoc Tukey Test was used to determine within a group difference. P values lower than 0.05 were considered significant. 
Author contributions: Conception-D.S.; Design-M.MB; D.S.; Supervision-M.MB.; Resources-D.S; M.MB; A.K; Materials-A.K.; Data Collection and/or Processing-A.K.; M.MB.; Analysis and/or Interpretation-A.K.; Literature Search-D.S.; Writing-D.S.; M.MB.; A.K.; Critical Reviews- D.S.; M.MB.; A.K.

Conflict of interest statement: All authors declare no conflict of interest.

Ethics committee approval: This study was approved by Ethics Committee of University of Sarajevo Faculty of Science.

\section{REFERENCES}

[1] US Food and Drug Administration. FDA Drug Safety Communication: FDA warns about several safety issues with opioid pain medicines; requires label changes. https://www.fda.gov/drugs/drug-safety-and-availability/fdadrug-safety-communication-fda-warns-about-several-safety-issues-opioid-pain-medicines-requires (accessed on 22 March 2016).

[2] Leppert W. Tramadol as an analgesic for mild to moderate cancer pain. Pharmacol Rep. 2009; 61: 978-992. [CrossRef]

[3] Yanarates O, Dogrul A, Yildirim V, Sahin A, Sizlan A, Seyrek M, Akgül Ö, Kozak O, Kurt E, Aypar U. Spinal 5-HT7 receptors play an important role in the antinociceptive and antihyperalgesic effects of tramadol and its metabolite, O-Desmethyltramadol, via activation of descending serotonergic pathways. Anesthesiology. 2010; 112: 696-710. [CrossRef]

[4] Kaneko K, Umehara M, Homan T, Okamoto K, Oka M, Oyama T. The analgesic effect of tramadol in animal models of neuropathic pain and fibromyalgia. Neurosci Lett. 2014; 562: 28-33. [CrossRef]

[5] Brayfield A. Tramadol hydrochloride. In: Brayfield A. (Ed). Martindale: The complete drug reference. Pharmaceutical Press, London, 2014, pp.46-88.

[6] NCPDP recommendations for dose accumulation monitoring in the inpatient setting: Acetaminophen case model, version 1.0. Am J Health Syst Pharm. 2016; 73(15): 1144-1165. [CrossRef]

[7] Chandanwale AS, Sundar S, Latchoumibady K, Biswas S, Gabhane M, Naik M, Patel K. Efficacy and safety profile of combination of tramadol-diclofenac versus tramadol-paracetamol in patients with acute musculoskeletal conditions, postoperative pain, and acute flare of osteoarthritis and rheumatoid arthritis: a Phase III, 5-day open-label study. J Pain Res. 2014; 7: 455-463. [CrossRef]

[8] Raffa RB, Clark-Vetri R, Tallarida RJ, Wertheimer AI. Combination strategies for pain management. Expert Opinion on Pharmacotherapy. 2003; 4(10): 1697-1708. [CrossRef]

[9] Blough ER, Wu M. Acetaminophen: beyond pain and Fever- relieving. Front Pharmacol. 2011; 72(2): 1-6. [CrossRef]

[10] Merrill GF, Goldberg E. Antioxidant properties of acetaminophen and cardioprotection. Basic Res Cardiol. 2001; 96(5): 423-430. [CrossRef]

[11] Jaques-Robinson KM, Golfetti R, Baliga SS, Hadzimichalis NM, Merrill GF. Acetaminophen is cardioprotective against $\mathrm{H}_{2} \mathrm{O}_{2}$-induced injury in vivo. Exp Biol Med. 2008; 233(10): 1315- 1322. [CrossRef]

[12] Tripathy D, Grammas P. Acetaminophen inhibits neuronal inflammation and protects neurons from oxidative stress. J Neuroinflammation. 2009; 6(10): 1-9. [CrossRef]

[13] Bisaglia M, Venezia V, Piccioli P, Stanzione S, Porcile C, Russo C, Mancini F, Milanese C, Schettini G. Acetaminophen protects hippocampal neurons and PC12 cultures from amyliod beta-peptides induced oxidative stress and reduces NF-kappa B activation. Neurochem Int. 2002; 41(1): 43-54. [CrossRef]

[14] Vanderah TW. Pathophysiology of pain. Med Clin North Am. 2007; 91(1): 1-12. [CrossRef]

[15] Rawal N, Macquaire V, Catalá E, Berti M, Costa R, Wietlisbach M. Tramadol/paracetamol combination tablet for postoperative pain following ambulatory hand surgery: a double-blind, double-dummy, randomized, parallel-group trial. J Pain Res. 2011; 4: 103-110. [CrossRef]

[16] Raffa RB. Pharmacology of oral combination analgesics: rational therapy for pain. J Clin Pharm Ther. 2001; 26(4): 257264. [CrossRef]

[17] Filitz J, Ihmsen H, Günther W, Tröster A, Schwilden H, Schüttler J, Koppert W. Supra-additive effects of tramadol and acetaminophen in a human pain model. Pain. 2008; 136(3): 262-270. [CrossRef]

[18] McQuay H, Edwards J. Meta-analysis of single dose oral tramadol plus acetaminophen in acute postoperative pain. Eur J Anaesthesiol. 2003; 28: 19-22. 
[19] Thornton JR, Losowsky MS. Severe thrombocytopenia after paracetamol overdose. Gut. 1990; 31(10): 1159-1160. [CrossRef]

[20] Waris N, Kausar R, Waris N, Naz F, Raza A. Effect of extra panadol on blood and behavior of rats. J Bioanal Biomed. 2017; 9(4): 206-211. [CrossRef]

[21] Cascio MJ, DeLoughery TG. Anemia: evaluation and diagnostic tests. Med Clin North Am. 2017; 101(2): $263-284$. [CrossRef]

[22] Hossain MS, AminMR, Mostafa M, Hossain MJ, Hasan MM. Effects of oral administration of nonsteroidal antiinflammatory drugs: aspirin and paracetamol in mice. Bangladhes J Agri. 2003; 1(1): 67-70. [CrossRef]

[23] Bhaumik A, Sharma MC. Therapeutic efficacy of Liv. 52 in experimentally induced hepatopathy in sheep. J Appl Anim Res. 1993; 3(2): 137-142. [CrossRef]

[24] Azeemuddin M, Rafiq M, Anturlikar SD, Sharath Kumar LM, Patki PS, Babu UV, Shyam R. Extract of a polyherbal formulation ameliorates experimental nonalcoholic steatohepatitis. J Tradit Complement Med. 2016; 6(2): $160-167$. [CrossRef]

[25] Adams HR, Veterinary pharmacology and therapeutics, Iowa State University Press, Ames, USA 1995, pp.625.

[26] Oyedeji KO, Bolarinwa AF, Ojeniran SS. Effect of paracetamol (Acetaminophen) on haematological and reproductive parameters in male Albino rats. J Pharm Biol Sci. 2013; 4(6): 65-70.

[27] Sharma MC, Dixit SK, Lal SB, Bhaumik A, Baig J. Effect of a herbal preparation in experimentally induced hepatopathy in goats. Indian J Anim Sci. 1993; 63(6): 606-610.

[28] Ramesh N, Jayakumar K, Honnegowda H, Narayana K. Effect of diclofenac and nimesulide on haematology in dogs. Indian J Anim Sci. 2001; 71(3): 221-223.

[29] Samuel SA, Francis AO, Ayomide O, Onyinyechi UO. Effects of paracetamol-induced liver damage on some hematological parameters: red blood cell (RBC) count, white blood cell (WBC) count, and packed cell volume (PCV) in Wistar rats of either sex. Indo Am J Pharm Res. 2015; 5(7): 2593-2599.

[30] Brander GC, Pugh DM, Bywater RJ, Jenkins WL. Veterinary applied pharmacology and therapeutics, fifth ed., The Bath Press, Avon, UK 1991, pp.140-142.

[31] Ekam VS, Ebong PE. Serum protein and enzyme levels in rats following administration of antioxidant vitamins during caffeinated and non-caffeinated paracetamol induced hepatotoxicity. Niger J Physiol Sci. 2007; 22(1-2): 65-68. [CrossRef]

[32] Adedapo AA, Abatan MO, Olorunsogo OO. Effects of some plants of the spurge family on haematological and biochemical parameters in rats. Veterinarski Arhiv. 2007; 77(1): 29-38.

[33] Elyazji NR, Abdel-Aziz I, Aldalou A, Shahwan O. The efects of Tramadol Hydrochloride administration on the hematological and biochemical profiles of domestic male rabbits. J Natural Engineering Studies. 2013; 21(2): 51-65.

[34] Molina PE. Opioids and opiates: analgesia with cardiovacular haemodynamic and immune implications en critical illness. J Intern Med. 2006; 259(2): 138-154. [CrossRef]

[35] Lamont LA, Mathews KA., Opioids, nonsteriodal anti-inflammatories and analgesic adjuvants. In: TranquilliJt, Thurmon JC, Grimm KA. (Eds). Lumb and Jones'Veterinary anesthesia and analgesia. Blackwell Publising Oxford, USA, 2007, pp.241-271.

[36] Elmanama AA, Abu Tayyem NES, Essawaf HN, Hmaid IM. Tramadol induced liver and kidney toxicity among Abusers in Gaza Strip, Palestine. Jordan J Biol Sci. 2015; 8(2): 133-137.

[37] Bishop LM, Fody PE, Schoe HL. Clinical chemistry principles, procedures correlations. Lippinoch Williams and Wilkins, Philadelphia, Hong Kong, 2005, pp.253-330.

[38] Aldiwan MA, Hassan Alzobidy AM, Younis MA. The effect of tramadol on some blood and biochemical parameters of male rats (Rattus norvegicus). Baghdad Sci J. 2015; 12(3): 496-502.

[39] Juei-Tang C, Liu IM, Tzong-Cherng C, Thing-Fong T, Feng-Hwa L, Chih Jen C. Plasma glucose lowering effect of tramadol in streptozotocin-induced diabetic rats. Diabetes. 2001; 50(12): 2815-2821. [CrossRef]

[40] Peyriêre H, Villiet M, Albert V,Creus M. Hypoglycemia related to tramadol therapy. French Pharmacol. 2004; 18(2): 215-268.

[41] Goeringer KE, Logan BK, Christian GD. Identification of tramadol and its metabolite in blood from drug-related death and drug-impaired-drivers. J Anal Toxicol. 1997; 21(7): 529-537. [CrossRef] 
[42] Hamad AA, Torad FA, Thabet NS, Gadallah SM. Effect of tramadol versus fentanyl on some hematological and serum biochemical parameters in dogs. Alexandria J Vet Sci. 2016; 50(1): 122-129. [CrossRef]

[43] Costa PF, Nunes N, Belmonte EA, Moro JV, Lopes PCF. Hematologic changes in propofol-anesthetized dogs with or without tramadol administration. Arq Bras Med Vet Zootec. 2013; 65(5): 1306-1312. [CrossRef]

[44] Sheng J, Hong-Gang, De-Zhang L, Jin-Long H, Xu-Dong S, Yue W, Hong-Bin W. Effects of the tiletamine/zolazepamxylazine-tramadol combination on plasma oxidative status and haematological indicators in miniature pigs. Acta Vet Brno. 2014; 83: 145-149. [CrossRef]

[45] Teixeira LG, Martins LR, Schimites PI, Dornelles GL, Aiello G, Oliveira JS, da Silva FC, Brum BT, Walter TM, Andrade CM, Soares AV. Evaluation of postoperative pain and toxicological aspects of the use of dipyrone and tramadol in cats. J Feline Med Surg. 2019; 21(5): 1-9. [CrossRef]

This is an open access article which is publicly available on our journal's website under Institutional Repository at http://dspace.marmara.edu.tr. 